\title{
Case Report \\ Life-Threatening Laryngeal Edema and Hyponatremia during Hysteroscopy
}

\author{
Barbara Wegmüller, ${ }^{1,2}$ Kerstin Hug, ${ }^{3}$ Charlotte Meier Buenzli, ${ }^{4}$ Bernd Yuen, ${ }^{1,5}$ \\ Marco Maggiorini, ${ }^{1}$ and Alain Rudiger ${ }^{1}$ \\ ${ }^{1}$ Medical Intensive Care Unit, University Hospital Zurich, Raemistraße 100, 8091 Zurich, Switzerland \\ ${ }^{2}$ Department of Anesthesiology, Balgrist University Hospital, 8008 Zurich, Switzerland \\ ${ }^{3}$ Gynecology and Obstetrics, Canton Hospital Nidwalden, 6370 Stans, Switzerland \\ ${ }^{4}$ Anesthesiology and Intensive Care, Canton Hospital Nidwalden, 6370 Stans, Switzerland \\ ${ }^{5}$ Intensive Care Unit, Hospital Bülach, 8180 Bülach, Switzerland \\ Correspondence should be addressed to Alain Rudiger, alain.rudiger@usz.ch
}

Received 18 November 2010; Accepted 27 January 2011

Academic Editor: Andrew F. Shorr

Copyright (C) 2011 Barbara Wegmüller et al. This is an open access article distributed under the Creative Commons Attribution License, which permits unrestricted use, distribution, and reproduction in any medium, provided the original work is properly cited.

We report on a 43-year-old patient undergoing a hysteroscopic myomectomy. After 80 minutes of operation, the patient developed laryngeal edema, requiring emergency tracheostomy. Hyponatremia (serum sodium $78 \mathrm{mmoL} / \mathrm{L}$ ) indicated an irrigation fluid absorption. The patient developed shock, acute respiratory distress syndrome, acute renal failure, and diffuse intravascular coagulopathy. Resuscitation including continuous venovenous hemodiafiltration was required. Finally, the patient made a full clinical recovery. Hysteroscopy usually has low risks. However, absorption of the irrigation fluid can result in life-threatening fluid overload and electrolyte disturbances. Accurate fluid balancing and limiting the operation time may prevent these complications.

\section{Introduction}

Hysteroscopy is a routine procedure for diagnosis and treatment of abnormal uterine bleeding and infertility assessment $[1,2]$. Jansen et al. described an overall risk for hysteroscopy of $0.28 \%$ and a risk for hysteroscopic myomectomy of $0.75 \%$ [3]. However, it can result in potentially severe and lifethreatening complications as reported in this case.

\section{Case Description}

A 43-year-old woman with intracavitary myomas underwent an elective hysteroscopy because of excessive uterine bleeding. She had hysteroscopic and laparotomic enucleation of myomas two and twelve years ago, respectively. A hysterectomy was recommended, but the patient refused.

The preoperative clinical assessment revealed a healthy woman with American Society of Anesthesiology (ASA) physical status I. Preoperative laboratory testing including red cell and platelet counts, coagulation parameters, electrolytes, and renal function tests were normal (Table 1). Lumbar spinal anesthesia (L3/4) with $10 \mathrm{mg}$ hyperbaric bupivacain $0.5 \%$ and supplemental $70 \mu \mathrm{g}$ clonidine was performed. Prior to the spinal puncture, the patient received an iv bolus of $0.1 \mathrm{mg}$ fentanyl. A propofol-infusion (15$20 \mathrm{mg} / \mathrm{h}$ ) was started when the anesthesized dermatome had reached $\mathrm{T} 5$. In addition, the patient received cefuroxim $1.5 \mathrm{~g}$ iv preoperatively. Standard monitoring including ECG, pulse oxymetry, noninvasive blood pressure, and urinary output measurements was installed. For optimal surgical visual field, the patient was placed in lithotomy position. The dilatation medium was a solution with $2.7 \%$ sorbitol and $0.54 \%$ mannitol, resulting in an osmolarity of $178 \mathrm{mosm} / \mathrm{L}$ (Purisole SM, Fresenius Kabi Germany). A hysteroscope (Storz, Germany) was used with regulation of inflow with a cuff at $100 \mathrm{mmHg}$. After 80 minutes of operation, a body temperature of $34^{\circ} \mathrm{C}$ and a fall of the oxygen saturation from $98 \%$ to $<70 \%$ were recorded. Clinically, an acute pulmonary edema and swelling of the neck were apparent. 
The surgeon was informed and emergency intubation was indicated. An induction dose of propofol $100 \mathrm{mg}$, fentanyl $0.1 \mathrm{mg}$, and rocuronium $40 \mathrm{mg}$ was administered. Because of massive laryngeal swelling, oral intubation failed. The vocal cords were not visible even with fiberoptic guidance. Finally, the placement of a laryngeal mask (LMA size 4 Laubscher, Switzerland) was successful, and an emergency tracheostomy was performed. By that time, 76 liters of irrigant fluid were used, but an exact irrigation fluid balance was not available. Urinary output was $1700 \mathrm{~mL}$, and blood loss was only minimal. By then, she had received $1600 \mathrm{~mL}$ Ringer-Lactat (B. Braun, Switzerland) iv. The patient became hypotensive and required noradrenaline. Arterial blood analysis revealed an acute hyponatremia $(78 \mathrm{mmoL} / \mathrm{L})$ and an acidosis with a $\mathrm{pH}$ of 6.91 (Table 1, Figure 1). Treatment with iv furosemide, hypertonic $\mathrm{NaCl}$, and bicarbonate $8.4 \%$ was initiated.

For further treatment, the patient was referred to the intensive care unit of a tertiary medical center. On admission, the patient required high doses of catecholamines (noradrenaline up to $100 \mu \mathrm{g} / \mathrm{min}$, pitressin up to $0.02 \mathrm{U} / \mathrm{min}$, and dobutamine up to $600 \mu \mathrm{g} / \mathrm{min}$ ). Her peripheral oxygen saturation was $81 \%$ with $\mathrm{FiO}_{2} \quad 1.0$, and the chest $\mathrm{X}$ ray on admission revealed a pulmonary edema (Figure 2). The arterial blood gas analyses revealed the following values: $\mathrm{pH} 6.9, \mathrm{pCO}_{2} 7.6 \mathrm{kPa}, \mathrm{pO}_{2} 7.8 \mathrm{kPa}$, bicarbonate 14.2 $\mathrm{mmoL} / \mathrm{L}$, base excess $-17 \mathrm{mmoL} / \mathrm{L}$, sodium $98 \mathrm{mmoL} / \mathrm{L}$, chloride $77 \mathrm{mmoL} / \mathrm{L}$, and lactate $5.3 \mathrm{mmoL} / \mathrm{L}$. The osmolarity was normal, but the osmogap was 65 (Norm $<5-$ $10 \mathrm{mosmol} / \mathrm{kg})$. Inhaled nitric oxide (5 ppm) was added, and oxygenation improved. Because sepsis was considered, piperacillin/tazobactam iv and low-dose corticosteroids were added. There was acute bleeding from the tracheostoma, epistaxis after insertion of a gastric tube, and uterine bleeding through an inflated Foley catheter placed intraoperatively. The administration of 8 packs of erythrocyte, 14 packs of fresh frozen plasma and one pack of platelets, $6 \mathrm{~g}$ of fibrinogen, $10 \mathrm{~g}$ of calcium, $5 \mathrm{~g}$ of aminocaproic acid, and $1000 \mu \mathrm{g}$ misoprostolum were necessary to stop the bleeding. In order to correct the acidosis and to remove the absorbed irrigation fluid, a continuous venovenous hemodiafiltration was started (dose $40 \mathrm{~mL} / \mathrm{kg}$ bodyweight, anticoagulation with citrate, and blood flow $120 \mathrm{~mL} / \mathrm{min}$ ). The patient was sedated with midazolam. Her corneal reflexes were initially absent. An electroencephalography showed no signs of an encephalopathy although the blood ammonia level was $150 \mu \mathrm{mol} / \mathrm{l}$. Hypothermia of $33.2^{\circ} \mathrm{C}$ was still present.

Fortunately, the clinical course was favorable: the disseminated intravascular coagulopathy remained under control without any signs of further bleeding. Hyponatremia was corrected within 36 hours (Figure 1). A computed tomography scan of the head showed no cerebral edema, bleeding, or ischemia. After sedation stop, the patient woke up without any apparent neurological deficit. By day 7 , the patient was weaned from the ventilator. However, due to the swelling of the neck, the tracheostomy canula was left in situ as long as the patient was in the ICU. Renal function recovered, and acid-base metabolism was reestablished with continuous haemodiafiltration, which was running for a total of 5 days. Vasopressor support with noradrenaline was required as long

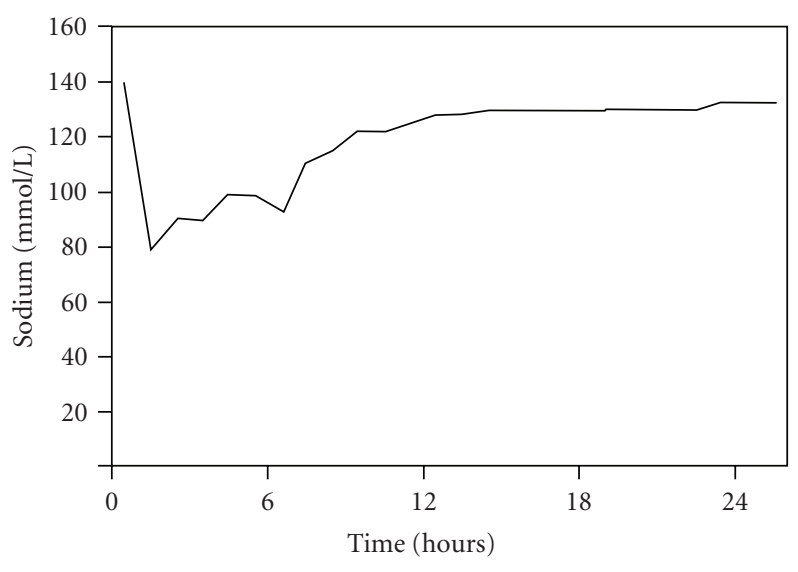

FIGURE 1: Postoperative correction of plasma sodium levels.

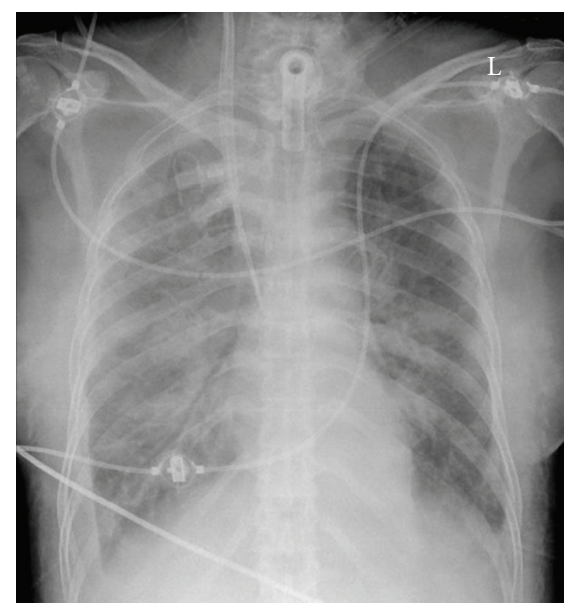

FIgure 2: The chest X-ray on ICU admission reveals pulmonary edema.

as the patient was on renal replacement therapy. The patient was discharged from the ICU on day 10 and from the hospital on day 30. One year later, she was well without any signs of long-term complications.

\section{Discussion}

During hysteroscopy, an irrigation fluid is necessary for dilatation and visualization the operating field. Fluid absorption appears to be more common during hysteroscopy than during transurethral resection of the prostate [4-6], the average amount being around $400-600 \mathrm{~mL}$. The principle mechanism of fluid absorption is direct absorption of the irrigating fluid into opened vessels during hysteroscopic resection of the myoma. The driving force is the intrauterine fluid pressure, which can be higher than the hydrostatic venous and arterial pressure. The intrauterine pressure can be influenced by the position of the fluid bag in relation to the patient and adjustments of the hysteroscope. The amount of fluid absorption is also influenced by the wound size and the resection time $[1,7,8]$. Hence, there is a correlation between the size of the resected myoma and the amount 
TABLE 1: Laboratory parameters.

\begin{tabular}{|c|c|c|c|c|c|}
\hline Laboratory parameters & Baseline & During surgery & On ICU admission & After $24 \mathrm{~h}$ & ICU discharge \\
\hline Sodium-mmoL/L (Norm 136-145) & 139 & 78 & 98 & 132 & 137 \\
\hline Chloride-mmoL/L (Norm 86-110) & - & - & 77 & 104 & 110 \\
\hline Osmolality—mmoL/kg (Norm 280-300) & - & - & 284 & 286 & 291 \\
\hline $\mathrm{pH}($ Norm 7.37-7.47) & - & 6.91 & 6.90 & 7.35 & 7.45 \\
\hline Base excess-mmoL/L $($ Norm \pm 2$)$ & - & -16.7 & -17.0 & -2.0 & 1.1 \\
\hline $\mathrm{HCO}_{3}^{-}-\mathrm{mmoL} / \mathrm{L}($ Norm $23-27)$ & - & 16.5 & 14.2 & 22.8 & 24.2 \\
\hline Platelet count- $1,000 / \mu \mathrm{l}($ Norm $143-400)$ & 169 & 160 & 207 & 28 & 171 \\
\hline D-dimer- $\mu \mathrm{g} / \mathrm{mL}($ Norm $<0.50)$ & - & 8.59 & 6.36 & 21.36 & 2.40 \\
\hline
\end{tabular}

of fluid absorption [7]. Our patient had a preoperative therapy with goserelinum in order to reduce the volume and vascularisation of the myoma. Nevertheless, the operation time exceeded the initially scheduled 60 minutes. Our case report supports the recommendation that the operation time for hysteroscopy should not be more than one hour. However, relevant fluid absorption can occur after only 15 minutes [9].

A preventive measure to recognize fluid absorption is an exact determination of the fluid balance by measuring the amount of fluid instilled into the uterus and the amount of fluid returned to the collection containers. It is recommended that the operative procedure is terminated when the fluid deficit reaches 1000 to $2000 \mathrm{~mL}$ [10]. At the time of symptoms, a total of 76 liters of irrigant fluids were used in our patient, which clearly exceeds the usually used 4-7 liters. Using the formula proposed by Serocki et al., we calculated a fluid overload of 11 liters [11]. This hypervolemia lead to the laryngeal swelling. The systemic inflammatory response syndrome with multiple organ failure might have resulted from hypoxemia, hypothermia, and fluid overload. To avoid fluid overload, restrictions of iv fluid and the use of diuretics are recommended during a longer procedure [7]. Serum electrolytes should be measured repeatedly, when more than $1000 \mathrm{~mL}$ are absorbed [7].

When hyponatremia develops within 24 hours, a rapid correction is indicated to prevent cerebral edema [12]. In our patient, plasma sodium was corrected within 36 hours, and there was no evidence of brain swelling. Premenopausal women with hyponatremia-induced postoperative encephalopathy have a higher morbidity and mortality and more frequently residual neurological damage than men or postmenopausal women [13]. However, in chronic hyponatremia, the correction of the plasma sodium concentration has to be less than $8 \mathrm{mmoL}$ in $24 \mathrm{~h}$ in order to prevent pontine myelinolysis [14].

Some specific symptoms depend on the solution used for hysteroscopy. For monopolar resectoscopes, an electrolytefree, hypotonic, and nonconductive solution is used (glycine $1.5 \%$ solution, sorbitol $2.7 \%$ with mannitol $0.54 \%$ mixture solution, or a mannitol 5\% solution). With glycine, there is a dose-dependent increase of symptoms such as visual disturbance (glycine is an inhibiting neurotransmitter) or excess of ammonia [15-17]. Sorbitol is metabolised to fructose and glucose. After metabolism, sorbitol and glycine leave free water behind. As they both dilute in the extra- and intracellular compartments, cellular edema and dilutional hyponatremia are the consequences. Mannitol is inert, distributes only in the extracellular space, and is excreted unchanged by the kidney. Mannitol 3\% has the largest sorbitol-mannitol mixture a medium and glycine $1.5 \%$ the smallest plasma dilutional effect $[18,19]$. The osmoticdiuretic effects of the substances lead to even more sodium loss and thereby worsen hyponatremia. With a monopolar resectoscope, it seems to be safest to use mannitol or sor$\mathrm{bitol} /$ mannitol mixtures because of fewer neurological and cardiovascular compromises [8]. With a bipolar resectoscope it is possible to use isotonic electrolyte solutions. However, the risk of excessive fluid absorption is still present.

This case emphasizes the importance of preventive measures in order to avoid a fluid absorption syndrome during hysteroscopy. First, close clinical observation and good communication between the anesthetist, patient, surgeon, and nurses during an endoscopic procedure are mandatory. This is facilitated with a regional anesthetic procedure. Second, an exact determination of the fluid balance is necessary. It is recommended that the procedure is terminated when the fluid absorption reaches $2000 \mathrm{~mL}$ [10]. Besides, restriction of iv fluids and the use of diuretics during a longer procedure are recommended [7]. Third, the resection time should not exceed 60 minutes [20] although the operation time seems to be less important than the total amounts of fluids used [8].

\section{Financial Support}

Intramural departmental sources.

\section{Conflict of Interests}

The authors have no conflict of interests.

\section{References}

[1] A. L. Magos, R. Baumann, G. M. Lockwood, and A. C. Turnbull, "Experience with the first 250 endometrial resections for menorrhagia," Lancet, vol. 337, no. 8749, pp. 1074-1078, 1991.

[2] L. D. Bradley, "Complications in hysteroscopy: prevention, treatment and legal risk," Current Opinion in Obstetrics and Gynecology, vol. 14, no. 4, pp. 409-415, 2002.

[3] F. W. Jansen, C. B. Vredevoogd, K. van Ulzen, J. Hermans, J. B. Trimbos, and T. C. M. Trimbos-Kemper, "Complications of 
hysteroscopy: a prospective, multicenter study," Obstetrics and Gynecology, vol. 96, no. 2, pp. 266-270, 2000.

[4] P. T. Chui, T. G. Short, A. K. L. Leung, P. E. Tan, and T. E. Oh, "Systemic absorption of glycine irrigation solution during endometrial ablation by transcervical endometrial resection," Medical Journal of Australia, vol. 157, no. 10, pp. 667-669, 1992.

[5] M. Goldenberg, M. Zolti, D. S. Seidman, D. Bider, S. Mashiach, and A. Etchin, "Transient blood oxygen desaturation, hypercapnia, and coagulopathy after operative hysteroscopy with glycine used as the distending medium," American Journal of Obstetrics and Gynecology, vol. 170, no. 1 I, pp. 25-29, 1994.

[6] O. Istre, J. Bjoennes, R. Naess, K. Hornbaek, and A. Forman, "Postoperative cerebral oedema after transcervical endometrial resection and uterine irrigation with $1.5 \%$ glycine," Lancet, vol. 344, no. 8931, pp. 1187-1189, 1994.

[7] A. H. Kim, M. D. Keltz, A. Arici, M. Rosenberg, and D. L. Olive, "Dilutional hyponatremia during hysteroscopic myomectomy with sorbitol-mannitol distention medium," Journal of the American Association of Gynecologic Laparoscopists, vol. 2, no. 2, pp. 237-242, 1995.

[8] R. G. Hahn, "Fluid absorption in endoscopic surgery," British Journal of Anaesthesia, vol. 96, no. 1, pp. 8-20, 2006.

[9] R. G. Hahn, "Early detection of the TUR syndrome by marking the irrigating fluid with $1 \%$ ethanol," Acta Anaesthesiologica Scandinavica, vol. 33, no. 2, pp. 146-151, 1989.

[10] K. B. Isaacson, "Complications of hysteroscopy," Obstetrics and Gynecology Clinics of North America, vol. 26, no. 1, pp. 39-51, 1999.

[11] G. Serocki, R. Hanss, M. Bauer, J. Scholz, and B. Bein, "Das gynäkologische 'TUR-syndrom," Anaesthesist, vol. 58, no. 1, pp. 30-34, 2009.

[12] M. L. Moritz and J. C. Ayus, "The pathophysiology and treatment of hyponatraemic encephalopathy: an update," Nephrology Dialysis Transplantation, vol. 18, no. 12, pp. 24862491, 2003.

[13] J. C. Ayus, J. M. Wheeler, and A. I. Arieff, "Postoperative hyponatremic encephalopathy in menstruant women," Annals of Internal Medicine, vol. 117, no. 11, pp. 891-897, 1992.

[14] J. G. Verbalis, S. R. Goldsmith, A. Greenberg, R. W. Schrier, and R. H. Sterns, "Hyponatremia treatment guidelines 2007: expert panel recommendations," American Journal of Medicine, vol. 120, no. 11, pp. S1-S21, 2007.

[15] R. G. Hahn, L. Sandfeldt, and C. R. Nyman, "Double-blind randomized study of symptoms associated with absorption of glycine $1.5 \%$ or mannitol $3 \%$ during transurethral resection of the prostate," Journal of Urology, vol. 160, no. 2, pp. 397-401, 1998.

[16] R. G. Hahn, H. Shemais, and P. Essén, "Glycine 1.0\% versus glycine $1.5 \%$ as irrigating fluid during transurethral resection of the prostate," British Journal of Urology, vol. 79, no. 3, pp. 394-400, 1997.

[17] J. Olsson, A. Nilsson, and R. G. Hahn, "Symptoms of the transurethral resection syndrome using glycine as the irrigant," Journal of Urology, vol. 154, no. 1, pp. 123-128, 1995.

[18] L. Sandfeldt and R. G. Hahn, "Comparison of urological irrigating fluids containing glycine and mannitol in volunteers," Prostate, vol. 41, no. 2, pp. 89-98, 1999.

[19] R. G. Hahn, A. Nilsson, and L. Ståhle, "Distribution and elimination of the solute and water components of urological irrigating fluids," Scandinavian Journal of Urology and Nephrology, vol. 33, no. 1, pp. 35-41, 1999.
[20] J. Desmond, "Serum osmolality and plasma electrolytes in patients who develop dilutional hyponatremia during transurethral resection," Canadian Journal of Surgery, vol. 13, no. 2, pp. 116-121, 1970. 


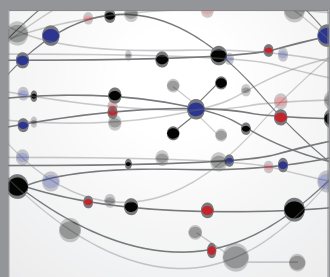

The Scientific World Journal
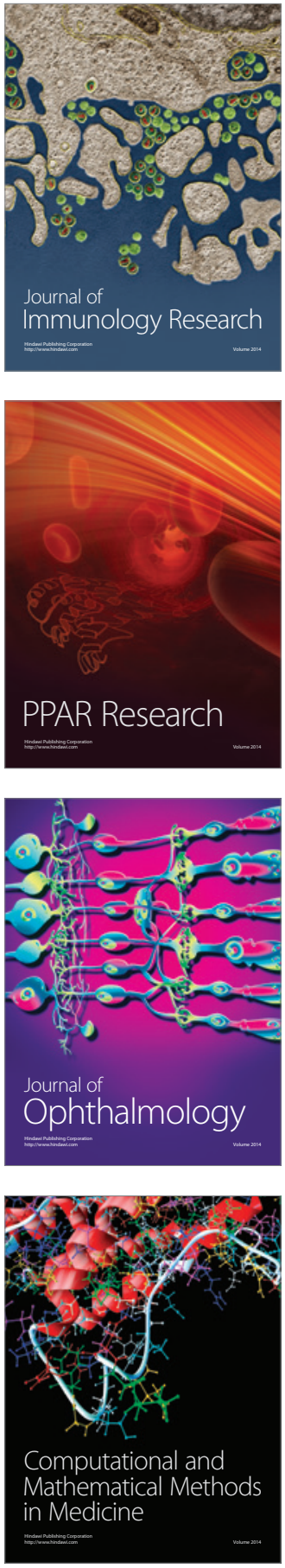

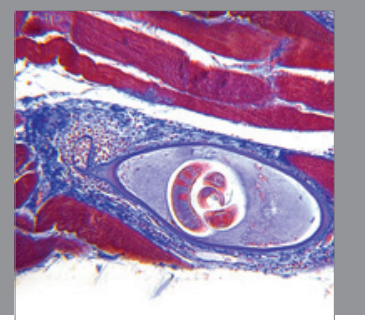

Gastroenterology

Research and Practice
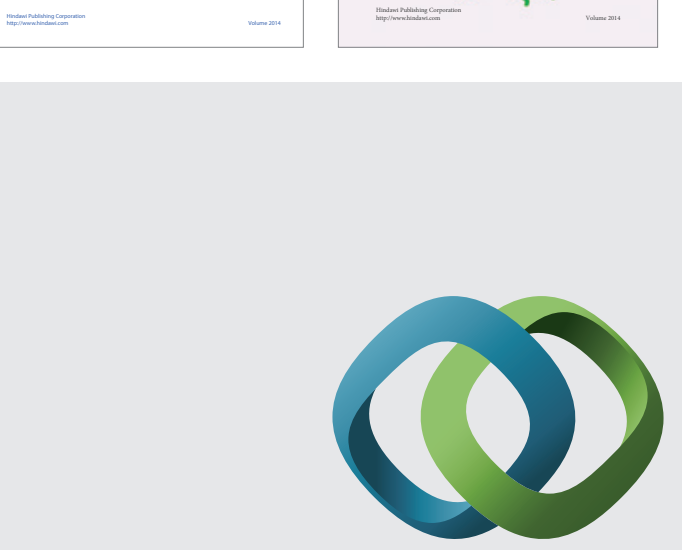

\section{Hindawi}

Submit your manuscripts at

http://www.hindawi.com
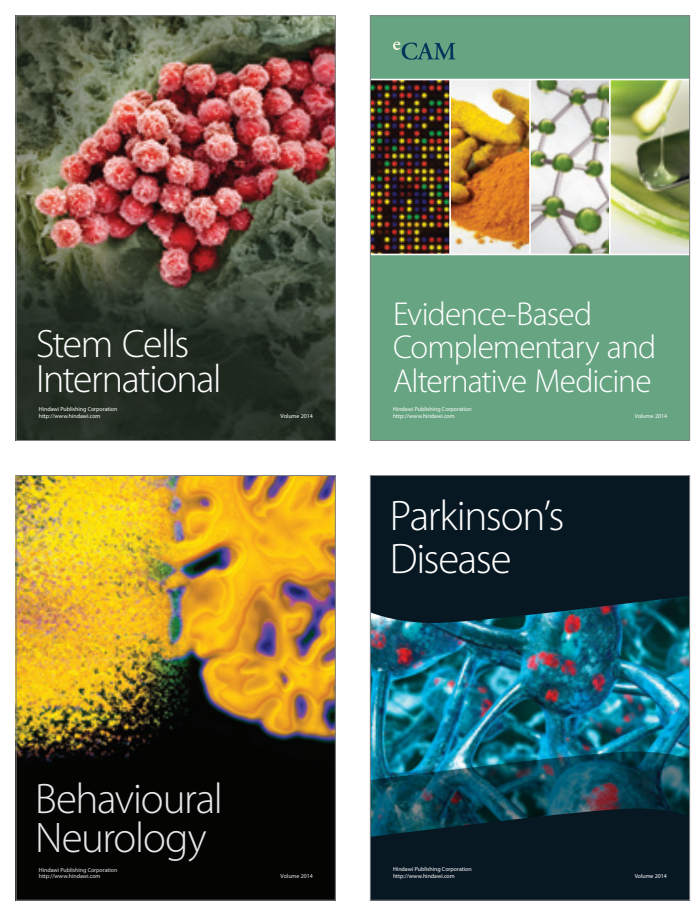

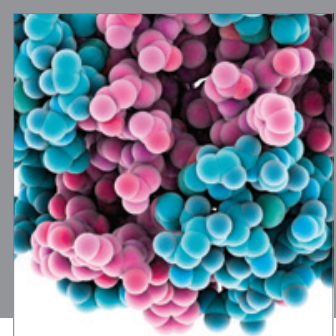

Journal of
Diabetes Research

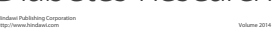

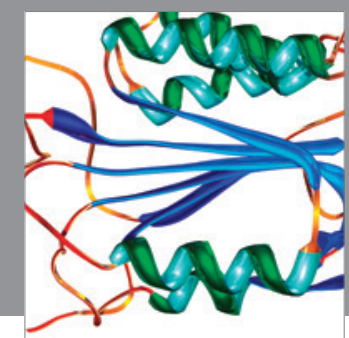

Disease Markers
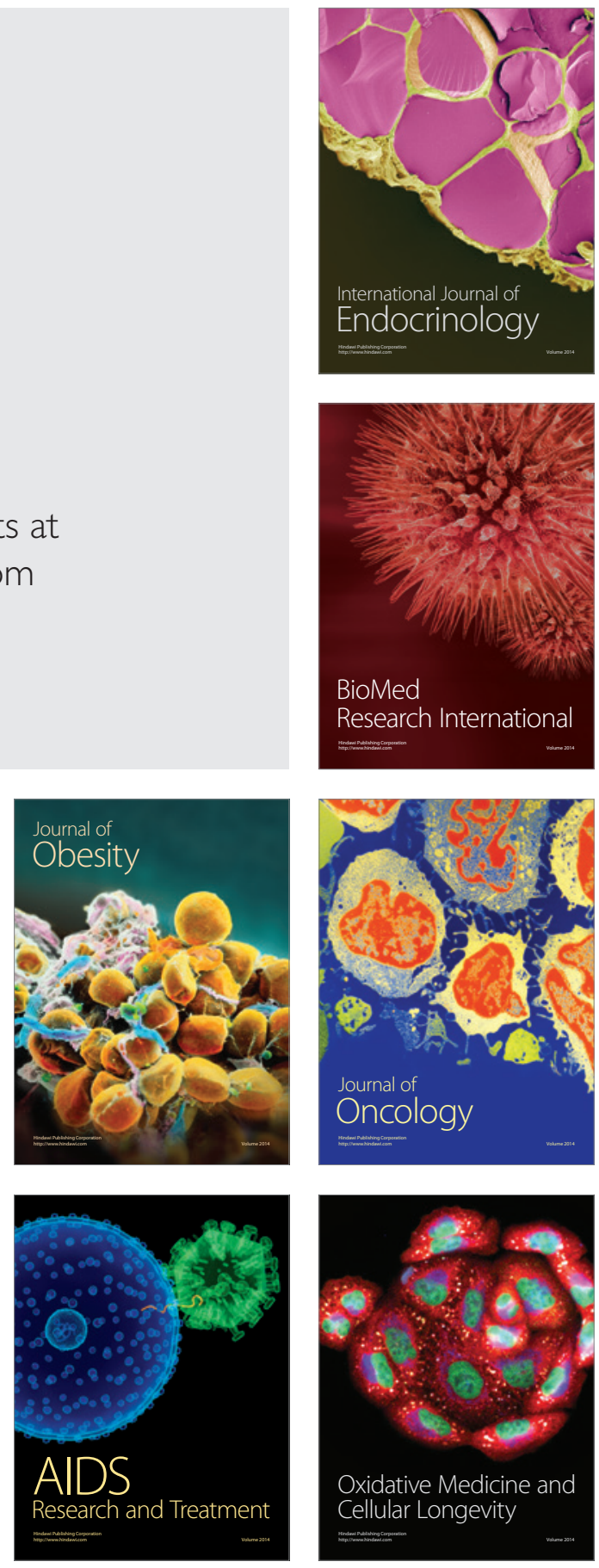